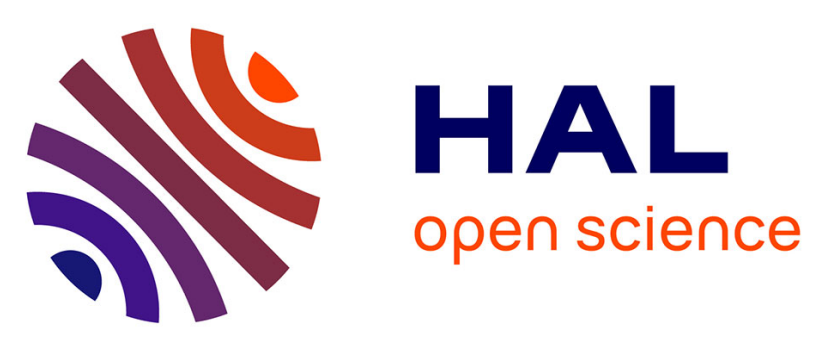

\title{
Interface depolarization field as common denominator of fatigue and size effect in $\mathrm{Pb}(\mathrm{Zr0.54Ti0.46)} \mathrm{O} 3$ ferroelectric thin film capacitors
}

\author{
Rachid Bouregba, N. Sama, Caroline Soyer, Gilles Poullain, Denis Remiens
}

\section{- To cite this version:}

Rachid Bouregba, N. Sama, Caroline Soyer, Gilles Poullain, Denis Remiens. Interface depolarization field as common denominator of fatigue and size effect in $\mathrm{Pb}(\mathrm{Zr} 0.54 \mathrm{Ti} 0.46) \mathrm{O} 3$ ferroelectric thin film capacitors. Journal of Applied Physics, 2010, 107, pp.104102-1-9. 10.1063/1.3380837 . hal-00549521

\author{
HAL Id: hal-00549521 \\ https://hal.science/hal-00549521
}

Submitted on 17 Nov 2021

HAL is a multi-disciplinary open access archive for the deposit and dissemination of scientific research documents, whether they are published or not. The documents may come from teaching and research institutions in France or abroad, or from public or private research centers.
L'archive ouverte pluridisciplinaire HAL, est destinée au dépôt et à la diffusion de documents scientifiques de niveau recherche, publiés ou non, émanant des établissements d'enseignement et de recherche français ou étrangers, des laboratoires publics ou privés. 


\title{
Interface depolarization field as common denominator of fatigue and size effect in $\mathrm{Pb}\left(\mathrm{Zr}_{0.54} \mathrm{Ti}_{0.46}\right) \mathrm{O}_{3}$ ferroelectric thin film capacitors
}

\author{
R. Bouregba, ${ }^{1, a)}$ N. Sama, ${ }^{2}$ C. Soyer ${ }^{2}$ G. Poullain, ${ }^{1}$ and D. Remiens ${ }^{2}$ \\ ${ }^{1}$ Laboratoire CRISMAT-ENSICAEN, CNRS UMR 6508, Université de Caen, Boulevard du Maréchal Juin, \\ 14050 Caen Cedex, France \\ IEMN-DOAE, CNRS UMR 8520, Cite Scientifique, 59655 Villeneuve d'Ascq Cedex, France
}

(Received 16 December 2009; accepted 8 March 2010; published online 18 May 2010)

\begin{abstract}
Dielectric, hysteresis and fatigue measurements are performed on $\mathrm{Pb}\left(\mathrm{Zr}_{0.54} \mathrm{Ti}_{0.46}\right) \mathrm{O}_{3}(\mathrm{PZT})$ thin film capacitors with different thicknesses and different electrode configurations, using platinum and $\mathrm{LaNiO}_{3}$ conducting oxide. The data are compared with those collected in a previous work devoted to study of size effect by R. Bouregba et al., [J. Appl. Phys. 106, 044101 (2009)]. Deterioration of the ferroelectric properties, consecutive to fatigue cycling and thickness downscaling, presents very similar characteristics and allows drawing up a direct correlation between the two phenomena. Namely, interface depolarization field $\left(E_{\text {dep }}\right)$ resulting from interface chemistry is found to be the common denominator, fatigue phenomena is manifestation of strengthen of $E_{\text {dep }}$ in the course of time. Change in dielectric permittivity, in remnant and coercive values as well as in the shape of hysteresis loops are mediated by competition between degradation of dielectric properties of the interfaces and possible accumulation of interface space charge. It is proposed that presence in the band gap of trap energy levels with large time constant due to defects in small nonferroelectric regions at the electrode-PZT film interfaces ultimately governs the aging process. Size effect and aging process may be seen as two facets of the same underlying mechanism, the only difference lies in the observation time of the phenomena. (C) 2010 American Institute of Physics. [doi:10.1063/1.3380837]
\end{abstract}

\section{INTRODUCTION}

Polarization fatigue in $\mathrm{Pb}\left(\mathrm{Zr}_{\mathrm{x}} \mathrm{Ti}_{1-\mathrm{x}}\right) \mathrm{O}_{3}$ (PZT) thin film capacitors is a source of failure that hinders the very large scale diffusion for applications as low cost, low power operation nonvolatiles ferroelectric memories. ${ }^{1}$ This phenomenon, which corresponds to a loss of switchable polarization under application of a longstanding repetitive stress voltage, is particularly pronounced when PZT capacitors are used with metallic electrodes, such as platinum. Although it may be overcome by using conducting oxide electrodes like $\mathrm{YBa}_{2} \mathrm{Cu}_{3} \mathrm{O}_{7},{ }^{2} \mathrm{SrRuO}_{3},{ }^{3} \mathrm{IrO}_{2},{ }^{4} \mathrm{RuO}_{2},{ }^{5} \mathrm{La}_{1-\mathrm{x}} \mathrm{Sr}_{\mathrm{x}} \mathrm{CoO}_{3},{ }^{6,7}$ and $\mathrm{LaNiO}_{3}{ }^{8}$, the physical mechanisms underlying the fatigue process are still far from being well defined. During the last decades, polarization fatigue has been the subject of a considerable number of experimental and theoretical works, as attested by the very abounding published literature. The complexity of the problem and the variety of the proposed models have been well illustrated in the review article by Tagantsev et al. $^{9}$ and in the more recent one by Lou, ${ }^{10}$ both showing how difficult it is to generate a consensual interpretation of the mechanism brought into play. The fact that fatigue process can be monitored, even suppressed, according to the nature of the electrodes pleads in favour of interface related phenomena. Many other kind of experiments support this notion, like for instance the drastic improvment of fatigue endurance observed on $\left(\mathrm{Pb}_{0.97} \mathrm{La}_{0.02}\right)(\mathrm{Ti}, \mathrm{Zr}, \mathrm{Sn}) \mathrm{O}_{3}$ ceramics after the surface has been polished. ${ }^{11}$ De facto, the models the most often cited for explaining the loss of polar-

${ }^{a)}$ Electronic mail: rachid.bouregba@ensicaen.fr. ization relied on interface related scenario like formation of low dielectric constant interface blocking layer, ${ }^{12}$ accumulation of oxygen vacancies at ferroelectric-electrode interfaces, ${ }^{13,14}$ inhibition of interface nucleation assisted by nearby electrode charge injection. ${ }^{9,15}$ Moreover it has been reported that PZT capacitors prone to fatigue polarization exhibit also thickness dependent dielectric and ferroelectric properties. This led some authors to establish a direct correlation between size effect and fatigue polarization by referring to an interface related mechanism. ${ }^{5,7,9,12,16-19}$

Surprisingly most of the published works often, even exclusively, address the fatigue problem through analysis of only one quantity, namely the remnant polarization $\left(P_{r}\right)$, whereas in practice the dielectric permittivity $\left(\varepsilon_{r}\right)$, the coercive field $\left(E_{c}\right)$ or more commonly the shape of the polarization loop are also affected during fatigue cycling. The seeking of a possible correlation between $\varepsilon_{r}, P_{r}, E_{c}$, and hysteresis shape, as well as the understanding of the manner by which this correlation is affected in the course of aging, may be a pertinent approach to discuss more reliably the underlying mechanism. From this point of view, Pawlaczyk et al. ${ }^{16}$ were among the rare ones who tried bringing enlightenments to this problem by using the concept of nearby electrode nucleation of opposite domains including interface space charge. This work also took credit for trying to investigate possible relationship between fatigue and size effect.

In the present article, the effects of fatigue upon dielectric and ferroelectric properties of PZT film capacitors are examined within the prism of recent results relating to size effect. It is shown that both phenomena are governed by the 


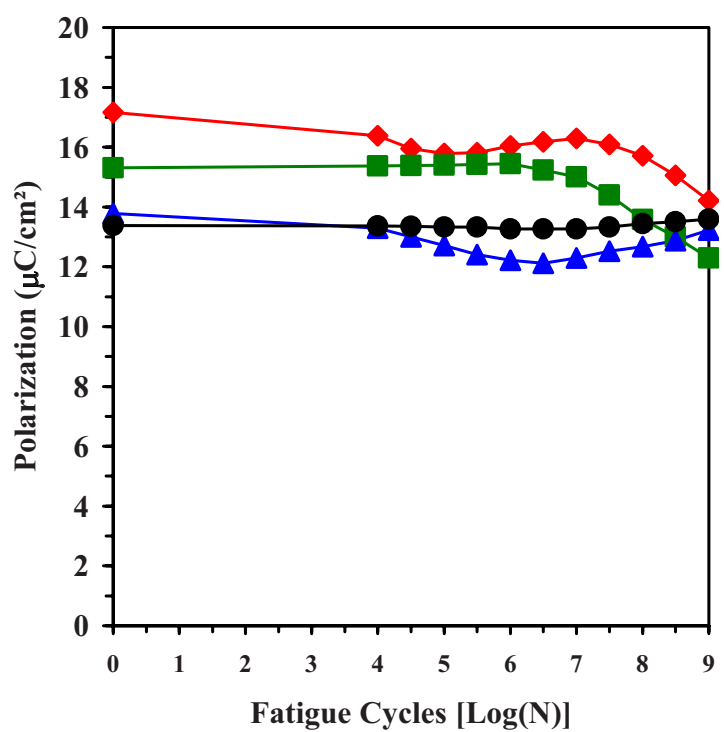

FIG. 1. (Color online) Remnant polarization as a function of cycle number for $400 \mathrm{~nm}$ thick $\mathrm{Pt} / \mathrm{PZT} / \mathrm{Pt} / \mathrm{TiO}_{\mathrm{x}} / \mathrm{SiO}_{2} / \mathrm{Si}$ (diamonds), $\mathrm{LNO} / \mathrm{PZT} /$ $\mathrm{Pt} / \mathrm{TiO}_{\mathrm{x}} / \mathrm{SiO}_{2} / \mathrm{Si}$ (squares), $\mathrm{Pt} / \mathrm{PZT} / \mathrm{LNO} / \mathrm{SiO}_{2} / \mathrm{Si}$ (triangles), and $\mathrm{LNO} / \mathrm{PZT} / \mathrm{LNO} / \mathrm{SiO}_{2} / \mathrm{Si}$ (circles) capacitors.

same quantity, the interface depolarization field. We emphasize that this work did not aim at modeling the process of fatigue progression itself, although some arguments are given in the last section for clarifying this point, but at interpreting the change in dielectric and ferroelectric properties picked up at two different instants of fatigue.

\section{EXPERIMENTAL}

Dielectric, hysteresis, and fatigue measurements were performed on $\mathrm{Pb}\left(\mathrm{Zr}_{0.54} \mathrm{Ti}_{0.46}\right) \mathrm{O}_{3}$ film capacitors with thicknesses ranging from $200-800 \mathrm{~nm}$. Platinum and lanthanum nickelate $\mathrm{LaNiO}_{3}$ (LNO) conducting oxide were used as electrodes. All the layers were deposited by rf magnetron sputtering. Ferroelectric capacitors with four different con- figurations were grown: $\mathrm{Pt} / \mathrm{PZT} / \mathrm{Pt} / \mathrm{TiO}_{\mathrm{x}} / \mathrm{SiO}_{2} / \mathrm{Si}$, $\mathrm{LNO} / \mathrm{PZT} / \mathrm{Pt} / \mathrm{TiO}_{\mathrm{x}} / \mathrm{SiO}_{2} / \mathrm{Si}, \mathrm{Pt} / \mathrm{PZT} / \mathrm{LNO} / \mathrm{SiO}_{2} / \mathrm{Si}$, and $\mathrm{LNO} / \mathrm{PZT} / \mathrm{LNO} / \mathrm{SiO}_{2} / \mathrm{Si}$. For details about the preparation method and the structural characterization of the films, please refer to an already published article. ${ }^{20}$ Fatigue measurements were performed by using a bipolar square signal of frequency $10 \mathrm{kHz}$ and with amplitude of 2.5 times $V_{c}$ whatever the thickness of the PZT capacitors. $V_{c}$ is the coercive voltage measured under condition of applied voltage that led all the samples to display the same maximum polarization before fatigue, i.e., $30 \mu \mathrm{C} / \mathrm{cm}^{2}$ (see further).

Figure 1 shows the variation with cycling of $P_{r}$ measured on the four types of structures with a thickness of 400 $\mathrm{nm}$. In the range of the cycle number studied, a loss of polarization of $17 \%-20 \%$ is observed for the two structures with platinum as bottom electrode, whereas $P_{r}$ remains almost constant when LNO is used as bottom electrode despite the small decrease followed by polarization restoration observed on the $\mathrm{Pt} / \mathrm{PZT} / \mathrm{LNO} / \mathrm{SiO}_{2} / \mathrm{Si}$ structure. Similar trends were obtained for the other thicknesses. Therefore utilization of platinum as bottom electrode seemed to be the determinant factor for the onset of the fatigue process, whereas the nature of the top electrode had almost no detrimental effect. In fact we will see that the top platinum electrode also contributed to degradation of the ferroelectric properties. The faculty of LNO bottom electrode to cancel, or just retard, the onset of the polarization fatigue has already been pointed out. ${ }^{8}$

Figure 2 displays the plot of inverse of the zero-volt small signal capacitance as a function of the thickness for each set of PZT capacitors before and after fatigue cycling. Except for the LNO/PZT/LNO structure, a systematic diminution of the capacitance after fatigue is observed especially pronounced when platinum is utilized as top electrode. Secondly all the plots follow a linear change in agreement with the serial capacitance model which assumes existence of low permittivity layers at the electrode-ferroelectric

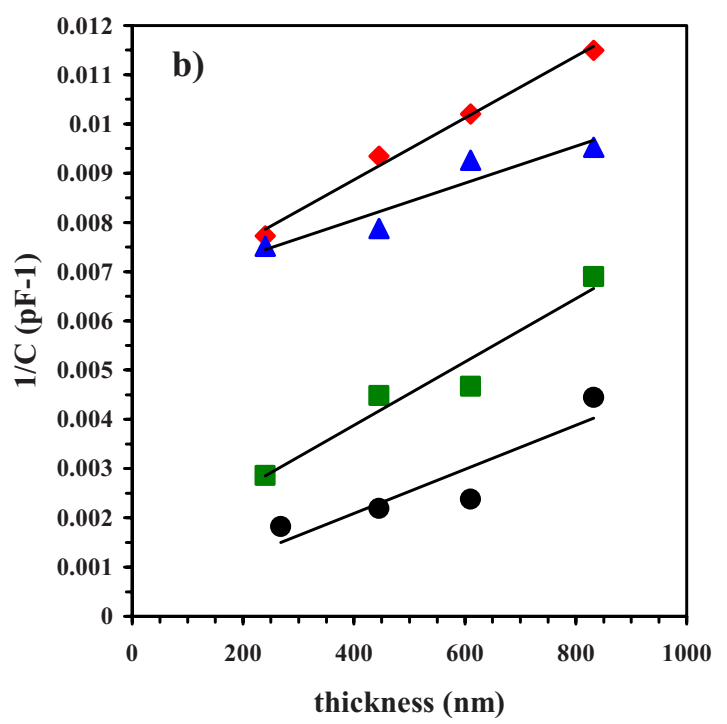

FIG. 2. (Color online) Plot of inverse of the small signal capacitance vs thickness with different electrode configuration: $\mathrm{Pt} / \mathrm{PZT} / \mathrm{Pt} / \mathrm{TiO} \mathrm{x}_{\mathrm{x}} / \mathrm{SiO} \mathrm{O}_{2} / \mathrm{Si}(\mathrm{dia}-$ monds), $\mathrm{LNO} / \mathrm{PZT} / \mathrm{Pt} / \mathrm{TiO}_{\mathrm{x}} / \mathrm{SiO}_{2} / \mathrm{Si}$ (squares), $\mathrm{Pt} / \mathrm{PZT} / \mathrm{LNO} / \mathrm{SiO}_{2} / \mathrm{Si}$ (triangles), and $\mathrm{LNO} / \mathrm{PZT} / \mathrm{LNO} / \mathrm{SiO}_{2} / \mathrm{Si}$ (circles), (a) before and (b) after fatigue. The frequency and the amplitude of the rf signal were $10 \mathrm{kHz}$ and $0.1 \mathrm{~V} \mathrm{rms}$, respectively. 
TABLE I. Summary of the values extracted from the plots of $1 / C=\mathrm{f}$ (thickness). Area of the ferroelectric capacitors was $1.8 \times 10^{-4} \mathrm{~cm}^{2}$.

\begin{tabular}{lcccc}
\hline \hline & $\mathrm{Pt} / \mathrm{PZT} / \mathrm{Pt} / \mathrm{TiO}_{\mathrm{x}} / \mathrm{SiO}_{2} / \mathrm{Si}$ & $\mathrm{LNO} / \mathrm{PZT} / \mathrm{Pt} / \mathrm{TiO}_{\mathrm{x}} / \mathrm{SiO}_{2} / \mathrm{Si}$ & $\mathrm{Pt} / \mathrm{PZT} / \mathrm{LNO} / \mathrm{SiO}_{2} / \mathrm{Si}$ & $\mathrm{LNO} / \mathrm{PZT} / \mathrm{LNO} / \mathrm{SiO} / \mathrm{Si}$ \\
\hline$\varepsilon_{f}$ (before fatigue) & 1070 & 1070 & 1600 & 1600 \\
$\varepsilon_{f}$ (after fatigue) & 1070 & 1070 & 1600 & 1600 \\
$C_{i}(\mathrm{nF})$ (before fatigue) & 0.435 & 0.91 & 0.33 & 3.33 \\
$C_{i}(\mathrm{nF})$ (after fatigue) & 0.16 & 0.77 & 0.15 & 3.33 \\
\hline \hline
\end{tabular}

interfaces. ${ }^{12,21}$ According to this model the interface capacitance $\left(C_{i}\right)$ is given by the origin ordinate and the bulk value of the dielectric constant $\left(\varepsilon_{f}\right)$ may be found from the slope. The results are summarized in Table I. The $\varepsilon_{f}$ value only depends on the nature of the bottom electrode, not on the upper one, because this quantity is mainly determined by the crystallographic orientation of the film. The difference in $\varepsilon_{f}$ value between the films grown on the two kinds of substrates is attributed to differences in microstructure. Most of all, we noticed that in both cases this quantity undergo no variation while fatiguing. By contrast the interfacial capacitances decreased except for the LNO/PZT/LNO structure which was also the one the less sensible to aging. Accordingly, polarization fatigue as well as diminution of the total capacitance presumably resulted from degradation of the interfaces properties, materialized by $C_{i}$, not from the bulk properties. The better fatigue endurance of the LNO/PZT/LNO capacitor may be correlated with the large $C_{i}$ value exhibited by this structure. Our observations are in agreement with previous experimental results by Lee et $a .^{5}$ and Grossmann et $a l^{22}$ We are however unable to affirm if this degradation resulted from a deterioration of the dielectric permittivity of the interface layer or rather from an increase in its thickness as suggested by Bratkovsky and Levanyuk. ${ }^{23}$

We note also that the apparent polarization endurance of the $\mathrm{Pt} / \mathrm{PZT} / \mathrm{LNO} / \mathrm{SiO}_{2} / \mathrm{Si}$ structure appears contradictory with the deterioration of interface capacitance and with the notion of coupling between size effect and fatigue as this structure was found to exhibit significant thickness dependence of $E_{c}{ }^{24}$ To answer this contradiction and go into details of our analysis, we present in Fig. 3 hysteresis measurements performed on fresh and fatigued capacitors.

The salient features may be summarized in three points: (1) loop deformations consisting in tilt are visible for all the structures, except for the one with LNO at both electrodes whose loop remains unchanged, (2) the tilt is accompanied by diminution of $P_{r}$ each time platinum is utilized as bottom electrode and (3) by increase in $E_{c}$ when platinum is utilized as top electrode. Very similar characteristics were also observed for the other thicknesses. The two first points, correlated, are in agreement with the decline of the interface capacitance observed above and with the fatigue results of Fig. 1 in the sense that degradation of the interfaces properties presumably yielded a reduction in the field actually applied to the bulk ferroelectric layer. Concomitant decrease in the switchable polarization was thus expected, as well as tilt of the loops, in agreement with predictions by other authors. ${ }^{25-27}$ The third point raises two questions. Firstly about the reason why $E_{c}$ increased whereas at the same time
$C_{i}$ decreased, secondly about the possible correlation with the persistence of $P_{r}$ found for the $\mathrm{Pt} / \mathrm{PZT} / \mathrm{LNO} / \mathrm{SiO}_{2} / \mathrm{Si}$ structure.

\section{DISCUSSION}

Variation in the coercive field is one of the characteristic features of fatigue process and yet has not been the subject of extensive investigation, unlike loss of remnant polarization. Decrease in $E_{c}$ was most often reported even if sometimes increase may also be observed. ${ }^{8,16,28-31}$ It has been suggested that increase in $E_{c}$ depends on degradation of the leakage property which sometimes may accompany fatigue. ${ }^{9}$ Although this is true for the structures in which existence of conduction currents is indeed revealed by loops with rounded shape, the progressive accumulation of space charge at the interfaces is however another plausible explanation that must be considered, particularly in the structures involving substantial density of interface defects. This last assertion must be taken in the perspective of a possible connexion with increased $E_{c}$ observed in fresh ferroelectric films of reduced thickness, which is attributable to the presence of such defects. ${ }^{24}$

It has been pointed out since one decade ago that interface passive layers with low permittivity are inappropriate to interpret the thickness dependence of $E_{c}$ unless static potential resulting from interface charge is considered. ${ }^{7,32,33}$ In a recent article, investigation of PZT capacitors, the same as those studied in the present paper, led the authors to identify the depolarization field $\left(E_{\mathrm{dep}}\right)$ inherent to interface chemistry as being the vector of the different facets of size effect. ${ }^{24}$ Deterioration of $\varepsilon_{r}$ and $P_{r}$, increasing $E_{c}$ as well as elongation of hysteresis loop accompanying thickness downscaling were indeed explained by considering existence at the interfaces of small nonferroelectric regions with low permittivity. Moreover, presence in these regions of charged defects, mainly located at the upper Pt-film interface, was a necessary condition in explaining why in some cases $E_{c}$ was affected by thickness downscaling but not $P_{r}$. A mechanism of compensation of $E_{\text {dep }}$ by these defects was then invoked. In order to check if fatigue and size effect are governed by the same phenomena, we try now to interpret the hysteresis measurements by referring to this model. According to the original work, ${ }^{34}$ the total interface built-in potential $V_{b i}$ due to space charge may be estimated by plotting $E_{c}$ versus $1 / d$, where $d$ is the film thickness. The $E_{c}$ fields are external values, i.e., the sum of the internal, or bulk, coercive values relating to the polarization due to the switching domains $\left(E_{f c}\right)$, and of the static field due to the interface space charge. So the correct extraction of $V_{b i}$, assumed constant, compels 

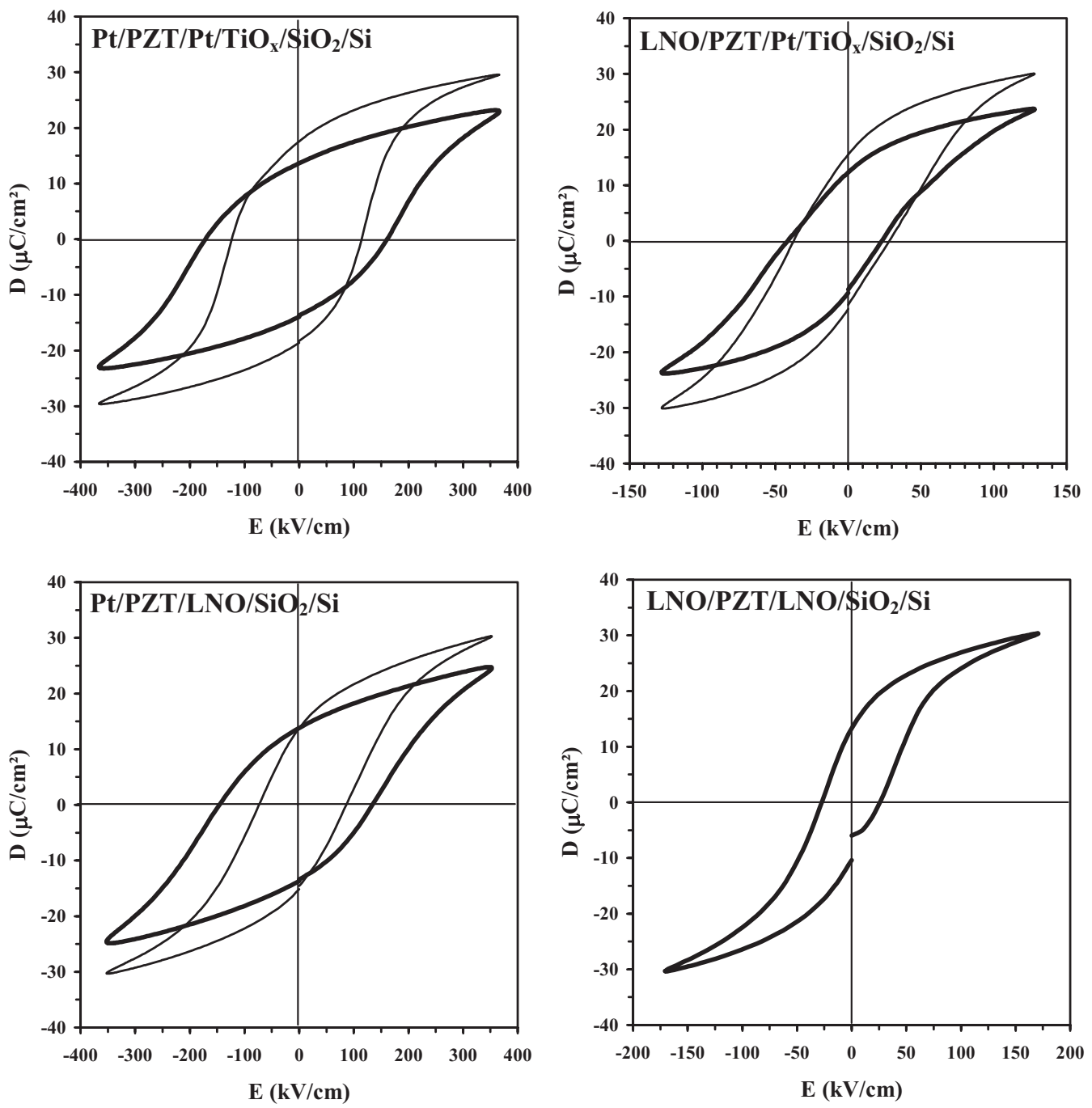

FIG. 3. Hysteresis loops of $400 \mathrm{~nm}$ thick PZT capacitors with different electrode configuration before fatigue (thin line) and after fatigue (thick line). The frequency measurement was $100 \mathrm{~Hz}$.

to take care that $E_{f c}$ remained almost constant whatever the perturbation undergone by the structure, i.e., consecutive to a change in the thickness or to fatigue cycling. This may be understood from the following relation: ${ }^{34}$

$$
E=E_{f}+\frac{\left(\frac{A D}{C_{i}}+V_{b i}\right)}{d},
$$

where $E$ and $E_{f}$ are the electric fields applied to the stacked structure and to the bulk ferroelectric layer, respectively. $D$ represents the electric displacement or the surface charge density on the capacitor plates and $A$ the area of the capacitor. It follows that $E_{c}$, the value reached by $E$ when $D=0$, is an inverse function of the thickness when $E_{f c}$ is constant. The comparative criterion we adopted is to make sure that all the samples exhibit almost the same maximum electric displacement $\left(D_{\max }\right)$ before and after fatigue cycling. In previous investigations devoted to size effects, we apply this criterion on fresh samples of different thicknesses. ${ }^{24,34}$ This procedure, achieved by adjusting the amplitude of the applied voltage, amounts to restore a similar inner polarization loop, close to saturation, in the bulk ferroelectric layer of each sample. In fine this simply returns to compensate for the voltage drop across the interface capacitance. Figure 4 shows the "corrected loops" and Fig. 5 the $E_{c}(1 / d)$ plots for $\mathrm{Pt} / \mathrm{PZT} / \mathrm{LNO} / \mathrm{SiO}_{2} / \mathrm{Si}$ and $\mathrm{LNO} / \mathrm{PZT} / \mathrm{LNO} / \mathrm{SiO}_{2} / \mathrm{Si}$ structures. Straight lines are obtained, the slope of which gives $V_{b i}$ [see Eq. (1)]. Very similar results were obtained for the two other structures grown on $\mathrm{Pt} / \mathrm{TiO}_{\mathrm{x}} / \mathrm{SiO}_{2} / \mathrm{Si}$. The values are summarized in Table II. As expected, elongation of the loops accompanied by increase in $P_{r}$ and $E_{c}$ values are visible for all the samples which displayed deterioration of the interface capacitance. Moreover a substantial increase in $V_{b i}$ is observed for the structures with upper platinum electrode, explaining the large $E_{c}$ values (note the different scales used for the $E$-axis on Fig. 4). We note also that these films exhibited non negligible $V_{b i}$ values from the virgin state, which caused the pronounced thickness dependence of $E_{c}{ }^{24}$ A further progressive accumulation of charge in the course of aging may therefore be invoked, presumably relating to a problem of interface chemistry as already pointed out. ${ }^{24}$ Last, we note that the $P_{r}$ value of the $\mathrm{Pt} / \mathrm{PZT} / \mathrm{LNO} / \mathrm{SiO}_{2} / \mathrm{Si}$ structure exceeds the one measured at the virgin state.

In Ref. 24 it was suggested that artificial increase in 

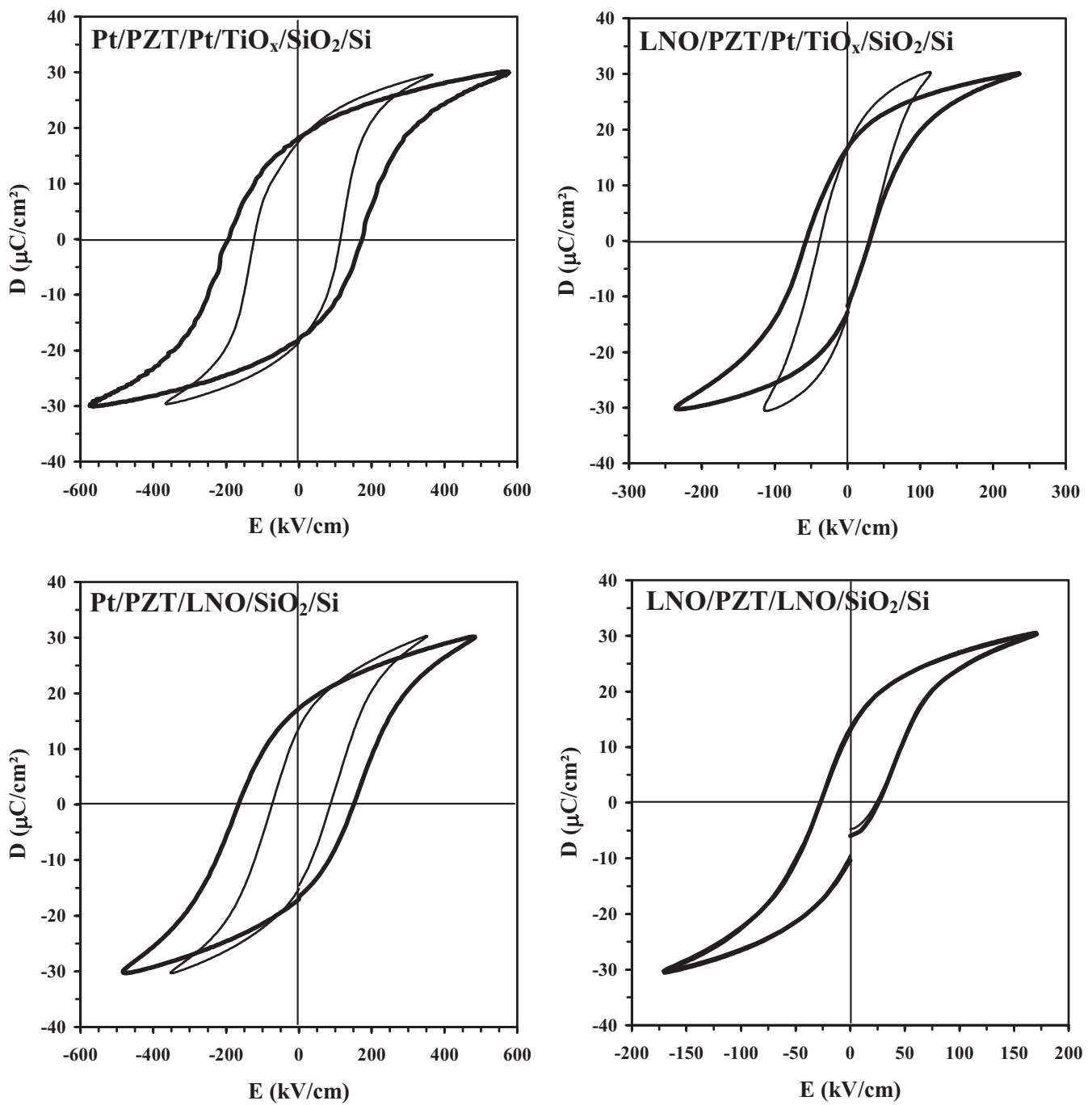

FIG. 4. Hysteresis loops idem as Fig. 3 except that the amplitude of applied voltage was adjusted in order to bring all the structures in the same condition of polarization, as determined by achievement of a same maximum electric displacement, before fatigue (thin line) and after fatigue (thick line).

remnant polarization may be caused by the presence of a substantial density of charge at the interfaces. The considered quantity was the value $D_{r}$ of $D$ which expression is

$$
D_{r}=\left[-\frac{\varepsilon_{O} \varepsilon_{f}}{d} V_{b i}+P_{f}\left(1-\frac{d_{i}}{d}\right)\right] \frac{1}{\alpha},
$$

with

$$
\alpha=1-\frac{d_{i}}{d}+\frac{\varepsilon_{f}}{d} \frac{d_{i}}{\varepsilon_{i}} .
$$

Moreover, the bulk ferroelectric layer is the center of a "zero volt no null electric field" given by

$$
E_{\mathrm{dep}}=-\left[V_{b i}+\frac{P_{f}}{\varepsilon_{O}} \frac{d_{i}}{\varepsilon_{i}}\right] \frac{1}{d \alpha},
$$

where $\varepsilon_{o}$ is the permittivity of free space, $P_{f}$ the polarization in the bulk ferroelectric layer, $d_{i}$ and $\varepsilon_{i}$ the total thickness and the permittivity of the interface layers, respectively. In the special situation where $d_{i} \ll d$, expressions of $D_{r}$ and $E_{\mathrm{dep}}$ become

$$
D_{r}=\left(\frac{-V_{b i} C_{f}+\mathrm{P}_{f} \mathrm{~A}}{A}\right) \frac{C_{i}}{C_{i}+C_{f}},
$$

and

$$
E_{\mathrm{dep}}=-\left[V_{b i} C_{i}+P_{f} A\right] \frac{1}{d\left(C_{i}+C_{f}\right)},
$$

where

$$
C_{i}=\frac{\varepsilon_{O} \varepsilon_{i} A}{d_{i}} \quad \text { and } \quad C_{f}=\frac{\varepsilon_{O} \varepsilon_{f} A}{d} .
$$

$C_{f}$ is the linear capacitance of the bulk ferroelectric layer whose thickness is assimilated to the total thickness $d$.

Two possible scenarios can be considered. First, the case where the interface potential is negligible while $C_{i}$ decreases. Then a deterioration of $D_{r}$ is expected, particularly pronounced as $C_{i}$ is reduced. Moreover the concomitant strengthen of $E_{\mathrm{dep}}$ tends to make the bulk ferroelectric layer deviating from the remnant polarization state, so a decrease in $P_{f}$ is expected in its turn. These effects, combined, may intensify the drop of $D_{r}$. At the same time the coercive fields are not affected because when $V_{b i}$ is null, $E_{c}$ equals $E_{f c}$ (see 

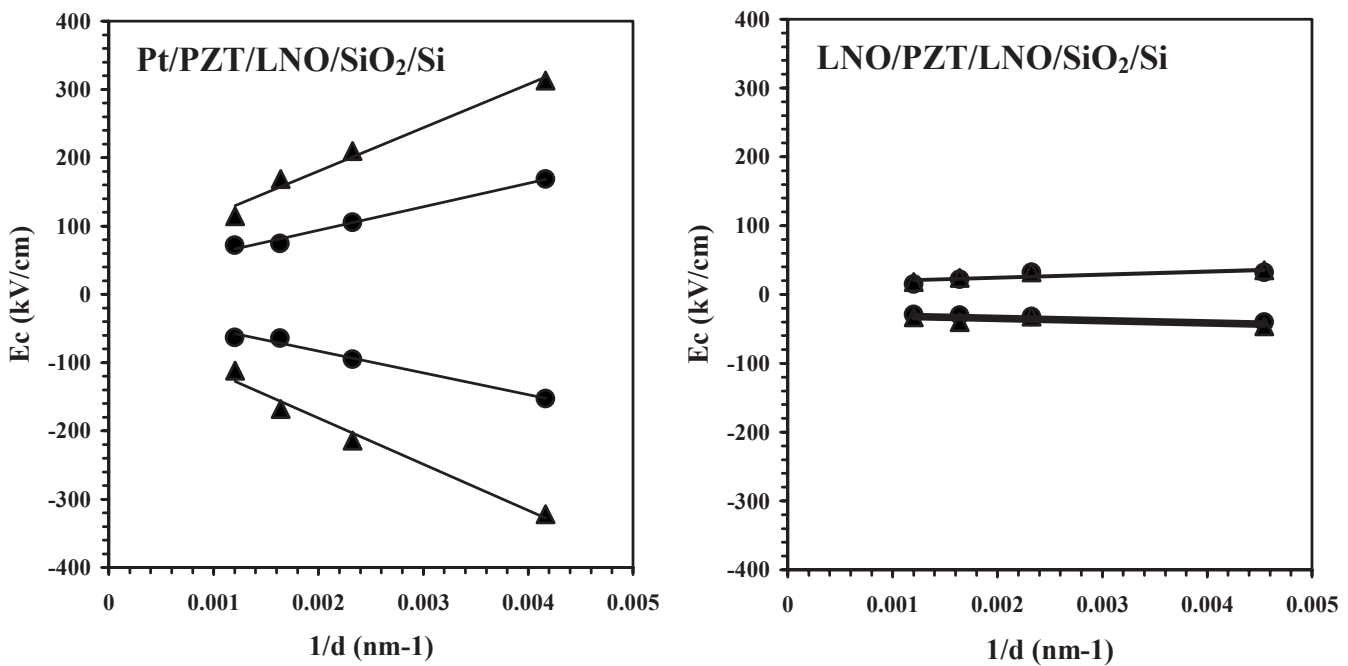

FIG. 5. Plot of coercive field $E_{c}$ vs $1 / d$ according to the model detailed in Ref. 34, for Pt/PZT/LNO/ $\mathrm{SiO}_{2} / \mathrm{Si}$ and $\mathrm{LNO} / \mathrm{PZT} / \mathrm{LNO} / \mathrm{SiO} / 2 \mathrm{Si}$ before fatigue (circles) and after fatigue (triangles).

Eq. (1)). This is why the serial connection of a standard capacitor with a ferroelectric one systematically reduces, for comparable $D_{\max }$, the $D_{r}$ value but does not alter $E_{c}$ [Refs. 7 and 35]. So, aging of a ferroelectric sample coming with elongation of hysteresis loops and loss of remnant values without variation in $E_{c}$, in the conditions of compensation mentioned above, may be seen as sign of development of interface depolarizing field. It has been suggested in a previous review article, ${ }^{9}$ that some of these features can also be explained either by bulk pinning of domains wall ${ }^{36}$ or by inhibition of interface nucleation. ${ }^{15}$ However, these mechanisms failed to explain the various aspects of size effect.

Unfortunately we note that the $\mathrm{LNO} / \mathrm{PZT} / \mathrm{Pt} / \mathrm{TiO}_{\mathrm{x}} /$ $\mathrm{SiO}_{2} / \mathrm{Si}$ structure, for which such effect was expected since $V_{b i}$ was low compared to structures using platinum as upper electrode, exhibits yet $D_{r}$ values and a negative coercive field $\left(E_{c}^{-}\right)$, respectively, equal to and larger than those achieved at the virgin state. We suspect that the increase in $V_{b i}$ (see Table II) associated with the slight increase in $E_{c}^{-}$(Fig. 4), although small, was however sufficient to hinder the effect of the depolarizing field (see below the discussion relating to compensation of $E_{\text {dep }}$ by interface charge). This situation was observed on other films with different thicknesses. We have to outline that, from a more general point of view, diminution of $D_{r}$ after fatigue and after adjusting $D_{\max }$ at the same value as before fatigue, should be delicate to observe because aging of ferroelectric capacitors typically comes with accumulation of interface charge, even very small according to the nature and quality of the electrodes, and/or with leakage, two phenomena likely to yield artificial increase in $D_{r}$. Moreover we emphasize that in the discussion above, $E_{\text {dep }}$ was defined as the field in the bulk ferroelectric layer in the short circuit situation and in the comparative situation where $D=D_{\max }$ $=$ constant. But it must be understood that any compensation, even cancellation, of this field due to interface charge is not contradictory with observation of fatigue polarization because a voltage drop across interface regions subsists if we consider the amplitude of the electric field. It was indeed established that the effect of interface charge is cancelled at the moments where the applied voltage reaches its maximum values because they correspond to the moments where the charge change sign. ${ }^{34}$ Since fatigue polarisation is typically estimated at constant amplitude of the applied voltage, then a drop of polarization due to the switching domains, hence of $D_{r}$, is still expected.

The second scenario includes the effects of substantial accumulation of interface charge and is very crucial to achieve a comprehensive understanding of all the aspects of fatigue. It is first necessary to remind the previous findings concerning the accurate consideration of the sign of $V_{b i}$. It was indeed established that the sign of $V_{b i}$ must be changed according to the time derivative of the applied voltage $\left(V_{\text {appl }}\right)$ in order to achieve a faithful simulation of the characteristic features of size effect, especially of the thickness dependence of $E_{c} \cdot{ }^{34} V_{b i}$ must indeed change sign each time $D$ reached its extremum values according to the following sequence: $V_{b i}$ must be positive when $\delta V_{\text {appl }} / \delta t$ is positive, otherwise $V_{b i}$ $<0$. So if we focus, for instance, on the positive remnant state $D_{r}^{+}$, then we must take $V_{b i}<0$. After the Eq. (4), the decrease in $D_{r}^{+}$consecutive to a deterioration of $C_{i}$ may then

TABLE II. Summary of the $V_{b i}$ values (in Volt) calculated from the slope of the $E_{c}(1 / d)$ plots and using the Eq. (1). Superscripts "+" and “-” are relating to the positive and negative values of coercive field, respectively.

\begin{tabular}{lccrr}
\hline \hline & $\mathrm{Pt} / \mathrm{PZT} / \mathrm{Pt} / \mathrm{TiO}_{\mathrm{x}} / \mathrm{SiO}_{2} / \mathrm{Si}$ & $\mathrm{LNO} / \mathrm{PZT} / \mathrm{Pt} / \mathrm{TiO}_{\mathrm{x}} / \mathrm{SiO}_{2} / \mathrm{Si}$ & $\mathrm{Pt} / \mathrm{PZT} / \mathrm{LNO} / \mathrm{SiO}_{2} / \mathrm{Si}$ & $\mathrm{LNO} / \mathrm{PZT} / \mathrm{LNO} / \mathrm{SiO}{ }_{2} / \mathrm{Si}$ \\
\hline $\mathrm{Vbi}^{+}$(before fatigue) & 3.87 & 0.031 & 3.43 & 0.43 \\
$\mathrm{Vbi}^{-}$(before fatigue) & -3.68 & -0.34 & -3.18 & -0.33 \\
$\mathrm{Vbi}^{+}$(after fatigue) & 6.83 & 0.054 & 6.35 & 0.45 \\
$\mathrm{Vbi}^{-}$(after fatigue) & -6.46 & -0.63 & -6.74 & -0.33 \\
\hline \hline
\end{tabular}



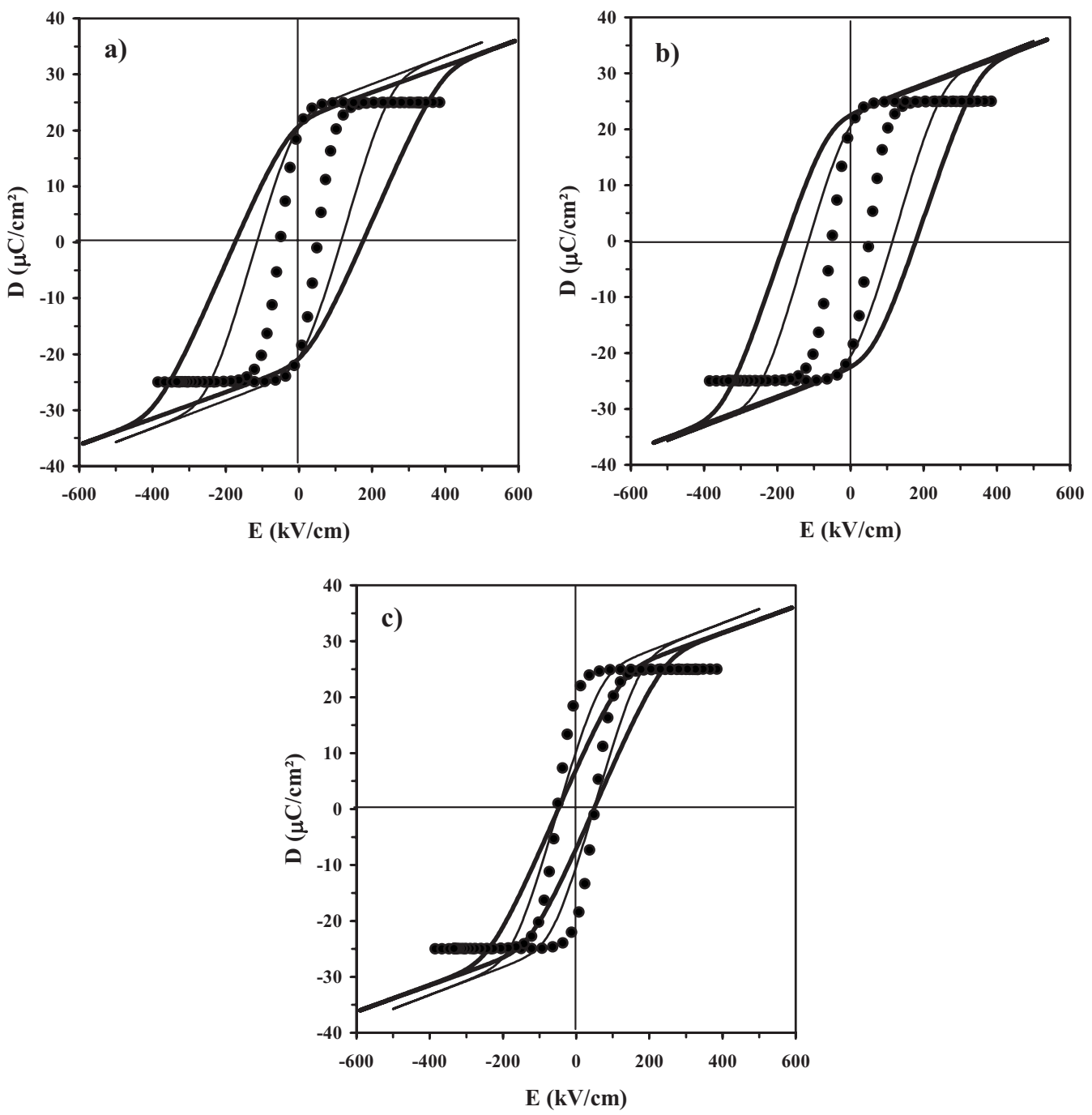

FIG. 6. Set of $D-E$ hysteresis loops calculated from the model presented in Refs. 25 and 34 . The loops before fatigue are in thin line, those after fatigue are in thick line. In dotted line is the inner $P_{f}-E_{f}$ loop, i.e., the polarization loop due to the switching domains in the bulk ferroelectric layer from which were computed all the external $D-E$ loops. The parameters used were the same as in Ref. 24 except those regarding the interface, chosen in such way to simulate three situations of fatigue: (a) fresh capacitors with $C_{i}=4.7 \mathrm{nF}$ and $V_{b i}= \pm 3 \mathrm{~V}$, fatigued capacitors with $C_{i}=2.6 \mathrm{nF}$ and $V_{b i}= \pm 6 \mathrm{~V}$, (b) fresh capacitors with $C_{i}=4.7 \mathrm{nF}$ and $V_{b i}= \pm 3 \mathrm{~V}$, fatigued capacitors with $C_{i}=3.75 \mathrm{nF}$ and $V_{b i}= \pm 6 \mathrm{~V}$, and (c) fresh capacitors with $C_{i}=4.7 \mathrm{nF}$ and $V_{b i}=0 \mathrm{~V}$, fatigued capacitors with $C_{i}=2.6 \mathrm{nF}$ and $V_{b i}=0 \mathrm{~V}$.

be more or less attenuated since in the example considered, $P_{f}$ is positive $\left(P_{f}\right.$ conserves the same sign as $P_{f r}^{+}$, despite the possible change in its magnitude due to $\left.E_{\text {dep }}\right)$. It should even be possible to achieve increasing $D_{r}^{+}$, i.e., overcompensation, if in the course of aging, the effects of accumulation of charge at the interfaces dominate those due to deterioration of the dielectric properties of the interfaces. At the same time, compensation of $E_{\mathrm{dep}}$ is expected from the Eq. (5), as well as increase in coercive fields which may be substantial according to $V_{b i}$ values [Eq. (1)]. Such compensation mechanism is suspected to be involved in the $\mathrm{Pt} / \mathrm{PZT} / \mathrm{LNO} / \mathrm{SiO}_{2} / \mathrm{Si}$ and $\mathrm{Pt} / \mathrm{PZT} / \mathrm{Pt} / \mathrm{TiO}_{\mathrm{x}} / \mathrm{SiO}_{2} / \mathrm{Si}$ structures. The very large $V_{b i}$ value, probably due to the poor quality of the upper interface, presumably explains why the first structure did apparently not undergo fatigue polarization despite the deterioration of the interface capacitance. The second one, however, exhibited increased deterioration of the overall interface capacitance due the platinum electrode at the bottom interface which was also detrimental for the di- electric properties (see Fig. 2 and Table I). Accordingly, it is likely that accumulation of charge on the upper interface of this structure was not adequate to oppose the strength of the depolarizing field, the latter becoming much more pronounced compared to the film with LNO at bottom electrode. Hence the significant drop of the remnant value (see Figs. 1 and 3). Last, if we compare the two structures which were visibly the most prone to fatigue polarization, i.e., $\mathrm{Pt} / \mathrm{PZT} / \mathrm{Pt} / \mathrm{TiO}_{\mathrm{x}} / \mathrm{SiO}_{2} / \mathrm{Si}$ and $\mathrm{LNO} / \mathrm{PZT} / \mathrm{Pt} / \mathrm{TiO}_{\mathrm{x}} / \mathrm{SiO}_{2} / \mathrm{Si}$ (see Fig. 1), we note that the loss of polarization was of the same order of magnitude. This apparently runs counter to the notion that oxide electrode tends to resorb fatigue polarization, unless conceding that accumulation of charge at the upper interface of the first structure hindered the expected increased drop of $D_{r}$.

In support of this model, we show in Fig. 6 the results of simulations obtained by utilizing the hyperbolic tangent function for description of $P_{f}-E_{f}$ polarization loop. ${ }^{25,34}$ Three typical situations, the most representative of the ex- 
perimental observations, were considered: (1) the case of decreasing $C_{i}$ and increasing $V_{b i}$ so that the coercive fields strongly increase but the remnant polarization meets the value before fatigue, (2) similar case as (1) but with a merest decrease in $C_{i}$ so that the remnant polarization exceed the value before fatigue, and (3) similar case as (1) but with $V_{b i}=0$. The required variations in $C_{i}$ and $V_{b i}$ were achieved by arbitrarily adjusting the physical parameters of the nonferroelectric interface regions. Though being qualitative, the simulations show that the main features discussed above are recovered.

Moreover striking similarities may be picked up between the shape of hysteresis loops of Figs. 4 and 6, and the one of the loops relating to analysis of size effects (see Figs. 2 and 5 in Ref. 24). From the model above indeed, the depolarizing field in the bulk ferroelectric layer is controlled by $C_{i}$ and thickness $d$. So, strengthen of $E_{\text {dep }}$ may occur in a ferroelectric sample of a given thickness where reduction in $C_{i}$ takes place in the course of time. This is the case of fatigue. On the other hand, strengthen of $E_{\text {dep }}$ may also arise after reducing the thickness of a ferroelectric capacitor in which the properties of the interface remained unchanged with downsizing. This is the case of size effect. Therefore $E_{\text {dep }}$ may be seen as the common denominator of both phenomena. In any case a mechanism of compensation of $E_{\mathrm{dep}}$, synonymous of accumulation of charge, should be considered so long as deterioration of coercive fields is observed. It should also be mentioned that in our previous work devoted to analysis of size effect, ${ }^{24}$ drop of $D_{r}$ with thickness downscaling was observed for the $\mathrm{LNO} / \mathrm{PZT} / \mathrm{Pt} / \mathrm{TiO}_{\mathrm{x}} / \mathrm{SiO}_{2} / \mathrm{Si}$ structure. In that case the effect of $E_{\text {dep }}$ upon $D_{r}$ was visible, unlike what was observed after fatigue, because the thickness was changed in much larger proportions than $C_{i}$ was.

\section{SUMMARY AND CONCLUDING REMARKS}

In this work it was found that the vector of fatigue and thickness effects was the depolarizing field arising from interface chemistry, as inferred from comparison of PZT capacitors with different electrodes: metallic and perovskite oxide. In every cases, change in dielectric permittivity, in remnant and coercive values, as well as in the shape of hysteresis loops are mediated by competition between degradation of the dielectric properties of the interfaces and possible accumulation of space charge. In a more general view point, fatigue resistance may ultimately be only apparent if one considers the only remnant value. The correct modeling of the underlying mechanism therefore demands comprehensive examination of hysteresis loops. For instance a constant remnant value accompanied by increase in coercive fields as well as tilt of the loop, is sign that must be discussed before construction of a model. More rigorously, further effects due to possible leakage currents should also be included.

As a corollary, following our previous conclusions, ${ }^{24,34}$ we infer that fatigue and size effect observed on our PZT films were both driven by extrinsic phenomena, namely the properties of the bulk ferroelectric layer were not diminished. In practice a great variety of behaviors may be ob- served according to the interface quality, the nature of the electrodes, the preparation process, or the crystallographic orientation. ${ }^{31}$

The fact that the depolarizing field was the common denominator between size effect and fatigue means that aging must not be seen as a phenomena occurring with time but rather as the slow manifestation, i.e., at long time scale, of a pre-existing phenomena, i.e., from the virgin state. In other words size effect and fatigue might involve interface states resulting from the presence in the band gap of trap energy levels with large time constants. A mechanism of trapping and releasing of injected charges ${ }^{37}$ should then explain the slow deterioration of the dielectric and electrostatic properties of the interfaces in the course of aging. From this view point we can qualitatively explain why the $\mathrm{LNO} / \mathrm{PZT} / \mathrm{LNO} / \mathrm{SiO}_{2} / \mathrm{Si}$ structure displayed size effect pretty much similar to the $\mathrm{LNO} / \mathrm{PZT} / \mathrm{Pt} / \mathrm{TiO}_{\mathrm{x}} / \mathrm{SiO}_{2} / \mathrm{Si}$ one, namely elongation of hysteresis loop and decrease in $D_{r}$ with thickness downscaling, ${ }^{24}$ while on the other hand the first structure did not fatigue unlike the second one. It is likely that the "all oxide structure" displayed better interfaces resulting from close chemical properties between the three layers, all with a perovskite structure. This is materialized by interface regions with the larger, but still finite, value found for $C_{i}$ and presumably with much larger time constant. This is certainly why no fatigue was observed on this structure in the range of cycle number investigated but should be observable in the very long run. Further efforts are required to achieve a quantitative description of fatigue including the mechanism of trapping in the framework of the model presented in this article.

${ }^{1}$ J. F. Scott, Ferroelectric Memories (Springer, New York, 2000).

${ }^{2}$ R. Ramesh, W. K. Chan, B. Wilkens, H. Gilchrist, T. Sands, J. M. Tarascon, V. G. Keramidas, D. K. Fork, J. Lee, and A. Safari, Appl. Phys. Lett. 61, 1537 (1992)

${ }^{3}$ C. B. Eom, R. B. Van Dover, J. M. Philips, D. J. Werder, J. H. Marshall, C. H. Chen, R. J. Cava, R. M. Fleming, and D. K. Fork, Appl. Phys. Lett. 63, 2570 (1993).

${ }^{4}$ T. Nakamura, Y. Nakao, A. Kamisawa, and H. Takasu, Appl. Phys. Lett. 65, 1522 (1994).

${ }^{5}$ J. J. Lee, C. L. Thio, and S. B. Desu, J. Appl. Phys. 78, 5073 (1995).

${ }^{6}$ R. Ramesh, H. Gilchrist, T. Sands, V. G. Keramidas, R. Haakenaasen, and D. K. Fork, Appl. Phys. Lett. 63, 3592 (1993).

${ }^{7}$ J. F. M. Cillessen, M. W. J. Prins, and R. M. Wolf, J. Appl. Phys. 81, 2777 (1997).

${ }^{8}$ M.-S. Chen, T.-B. Wu, and J.-M. Wu, Appl. Phys. Lett. 68, 1430 (1996).

${ }^{9}$ A. K. Tagantsev, I. Stolichnov, E. L. Colla, and N. Setter, J. Appl. Phys. 90, 1387 (2001).

${ }^{10}$ X. J. Lou, J. Appl. Phys. 105, 024101 (2009).

${ }^{11}$ W. Y. Pan, C. Q. Dam, Q. M. Zhang, and L. E. Cross, J. Appl. Phys. 66, 6014 (1989)

${ }^{12}$ P. K. Larsen, G. J. M. Dormans, D. J. Taylor, and P. J. van Veldhoven, J. Appl. Phys. 76, 2405 (1994).

${ }^{13}$ I. K. Yoo and S. B. Desu, Phys. Status Solidi A 133, 565 (1992).

${ }^{14}$ M. Dawber and J. F. Scott, Appl. Phys. Lett. 76, 1060 (2000).

${ }^{15}$ E. L. Colla, D. V. Taylor, A. K. Tagantsev, and N. Setter, Appl. Phys. Lett. 72, 2478 (1998)

${ }^{16}$ C. Z. Pawlaczyk, A. K. Tagantsev, K. Brooks, I. M. Reaney, R. Klissurska, and N. Setter, Integr. Ferroelectr. 8, 293 (1995).

${ }^{17}$ I. Stolichnov, A. Tagantsev, E. Colla, S. Gentil, S. Hiboux, J. Baborowski, P. Muralt, and N. Setter, J. Appl. Phys. 88, 2154 (2000).

${ }^{18}$ H. Z. Jin and J. Zhu, J. Appl. Phys. 92, 4594 (2002).

${ }^{19}$ X. J. Lou, M. Zhang, S. A. T. Redfern, and J. F. Scott, Phys. Rev. B 75, 224104 (2007).

${ }^{20}$ N. Sama, R. Herdier, D. Jenkins, C. Soyer, D. Remiens, M. Detalle, and R. 
Bouregba, J. Cryst. Growth 310, 3299 (2008).

${ }^{21}$ T. Hase, T. Sakuma, Y. Miyasaka, K. Hirata, and N. Hosokawa, Jpn. J. Appl. Phys., Part 1 32, 4061 (1993).

${ }^{22}$ M. Grossmann, O. Lohse, D. Bolten, U. Boettger, T. Schneller, and R. Waser, Appl. Phys. Lett. 80, 1427 (2002).

${ }^{23}$ A. M. Bratkovsky and A. P. Levanyuk, Phys. Rev. Lett. 84, 3177 (2000).

${ }^{24}$ R. Bouregba, N. Sama, C. Soyer, and D. Remiens, J. Appl. Phys. 106, 044101 (2009).

${ }^{25}$ S. L. Miller, R. D. Nasby, J. R. Schwank, M. S. Rodgers, and P. V. Dressendorfer, J. Appl. Phys. 68, 6463 (1990).

${ }^{26}$ C. J. Brennan, Ferroelectrics 132, 245 (1992).

${ }^{27}$ A. K. Tagantsev, M. Landivar, E. Colla, and N. Setter, J. Appl. Phys. 78, 2623 (1995).

${ }^{28}$ H. N. Al-Shareef, B. A. Tuttle, W. L. Warren, T. J. Headley, D. Dimos, J. A. Voigt, and R. D. Nasby, J. Appl. Phys. 79, 1013 (1996).

${ }^{29}$ S. B. Majumder, Y. N. Mohapatra, and D. C. Agrawal, Appl. Phys. Lett.
70, 138 (1997)

${ }^{30}$ E. Paton, M. Brazier, S. Mansour, and A. Bement, Integr. Ferroelectr. 18, 29 (1997).

${ }^{31}$ G. Le Rhun, G. Poullain, R. Bouregba, and G. Leclerc, J. Eur. Ceram. Soc. 25, 2281 (2005).

${ }^{32}$ A. K. Tagantsev, Ferroelectrics 184, 79 (1996).

${ }^{33}$ A. K. Tagantsev and I. A. Stolichnov, Appl. Phys. Lett. 74, 1326 (1999).

${ }^{34}$ R. Bouregba, G. Le Rhun, G. Poullain, and G. Leclerc, J. Appl. Phys. 99, 034102 (2006).

${ }^{35} \mathrm{R}$. Bouregba and G. Poullain, Proceedings of the 13th IEEE International Symposium on Applications of Ferroelectrics ISAF2002, Nara, Japan, 2002, (unpublished), p. 11.

${ }^{36}$ W. L. Warren, D. Dimos, B. A. Tuttle, G. E. Pike, R. W. Schwartz, P. J. Clews, and D. C. McIntyre, J. Appl. Phys. 77, 6695 (1995).

${ }^{37}$ G. Poullain, C. Cibert, and R. Bouregba, J. Appl. Phys. 106, 124105 (2009). 